\title{
Knowledge and Self-Reported Practice of Insulin Injection Device Disposal and Associated Factors among Diabetes Patients in Addis Ababa, Ethiopia: A Cross-Sectional Study
}

\section{Aynalem Loha}

Arbaminch University

\section{Fekadu Aga}

Addis Ababa University

Amanuel Fanta ( $\square$ amanuelfanta@gmail.com )

Hawassa College of Health Science https://orcid.org/0000-0002-0728-5286

\section{Research Article}

Keywords: Keywords: Diabetes, Injection device disposal, Knowledge, self-reported practice

Posted Date: February 1st, 2022

DOI: https://doi.org/10.21203/rs.3.rs-1318001/v1

License: (c) (i) This work is licensed under a Creative Commons Attribution 4.0 International License. Read Full License 


\section{Abstract \\ Background}

Poor disposal practices of insulin injection device among diabetes patients lead to the accumulation of sharps within the household and can potentially result in personal injury and injuries to people in the household and general community.

\section{Objective}

This study was aimed to assess the knowledge and self-reported practice of insulin injection device disposal and associated factors among diabetes patients in Addis Ababa, Ethiopia.

\section{Method}

A hospital based cross-sectional study was employed among 182 diabetes patients on follow-up at Diabetic Clinic of Tikur Anbesa Specialized Hospital - the Ethiopia's single largest referral hospital - in Addis Ababa. Descriptive data was summarized using frequencies and percentage. Binary logistic regression was used to analyze the relationships between variables. Data was analyzed using SPSS version 25.

\section{Results}

About $54 \%$ of the participants had inadequate knowledge towards safe insulin injection waste disposal. More than two-thirds $(73 \% \%)$ of respondents had poor self-reported practice of insulin device disposal. Participants in age group between 25 and 39 years $(A O R=8.012,95 \% \mathrm{Cl}=2.168,29.600, \mathrm{p}$-value $=0.02)$ and those with type 1 diabetes $(A O R=2.14,95 \% \mathrm{Cl}=1.12,4.00, \mathrm{p}$-value $=0.020)$ were more likely to have adequate knowledge of insulin injection device disposal. But, participants who were urban residents ( $A O R=0.197,95 \% \mathrm{Cl}=0.053,0.730, p-v a l u e=0.015)$, received information from pharmacist or friends $(A O R=0.358,95 \% \mathrm{Cl}=0.129,0.990, \mathrm{p}$-value $=0.036)$, and used insulin for 5 years or bellow $(\mathrm{AOR}=0.332,95 \% \mathrm{Cl}=0.154,0.710, \mathrm{p}$-value $=0.014)$ were less likely to have adequate knowledge. Participants with type 1 diabetes $(A O R=2.1,95 \% \mathrm{Cl}=1.054,4.200, \mathrm{p}$-value $=0.035)$ and who had adequate knowledge $(A O R=2.5,95 \% \mathrm{Cl}=1.025,6.300$, $\mathrm{p}$-value $=0.044)$ were more likely to have good self-reported practice of insulin injection device disposal.

\section{Conclusion}

This study revealed that diabetes patients in Addis Ababa had poor knowledge and self-reported practice of insulin injection device disposal.

\section{Introduction}

Diabetes Mellitus (DM) is a group of metabolic diseases characterized by hyperglycemia (1). It is a serious long term condition with major impact on the lives and wellbeing of individuals, families, and societies worldwide. It is among the top 10 causes of death in adults, and was estimated to have caused four million deaths globally (2). 
The management and control of diabetes mellitus involves self- injection of insulin at home. Various kinds of medical instruments like insulin pens, needles, and syringes are used for self-injection of insulin. These medical instruments are among what the World Health Organization (WHO) has described as sharps that can cause cuts or puncture wounds $(3,4)$. These sharp injuries can be associated with the transmission of blood borne infections such as HIV and hepatitis $B$ and $C$ virus.

Improper needle disposal is a global public health problem in both developed and developing countries(5). Proper disposal of used medical sharps is the neglected component of essential measures to prevent health care hazards (3-6). Poor disposal practices of insulin injection devices among diabetes patients lead to the accumulation of sharps within the household and potentially results in personal injury, and injuries to people in the household and to the general community. This results in the spread of blood born infections such as $30 \%$ prevalence of hepatitis $B$ virus, $1.8 \%$ of hepatitis $\mathrm{C}$ virus, and $0.3 \%$ of human immune deficiency virus (5).

Diabetes patients continuously use insulin injection devices as part of their daily diabetes self-care, however majority of them are unaware of how to properly dispose these injection devices. Moreover, some diabetes patients simply throw their used needles in the trash bins or flush them

down into toilet and this poses a risk of injury or spread of infections (6). Factor associated with unsafe disposal of sharps by diabetes patients include lack of information about how and where to dispose, lack of proper advice from healthcare practitioners, lack of awareness about the danger related with unsafe disposal, wrong perception on sharp disposal, and self-administration of insulin by diabetes patients and long duration of diabetes (3).

A study done India showed that only $3.6 \%$ of respondents had correct knowledge about safe disposal method of insulin injection devices(7). Furthermore, the same study showed that about two-thirds of the participants (65.9\%) had moderate level of knowledge while less than one third of them (23.8\%) had the high level for knowledge and (10.3\%) respondents had low level of knowledge about household sharp disposal management. A study from the United Arab Emirate, however, reported that approximately $60 \%$ of patients know how to dispose used sharps and $70 \%$ are aware of the hazards of unsafe disposal of sharps (6).

According to a study from Pakistan, majority of the participants ( $>90 \%)$ improperly disposed syringes, needles, and lancets in the household garbage collection bins despite the fact that almost half of the patients were educated about the proper disposal of sharps devices (8). The same study further described that most of the patients disposed used devices along with other household waste into the same garbage collection bin and few patients reported using a sharps disposal box to dispose of used insulin injection devices.

A study conducted in Indian reported that few respondents (14.2\%) had received information on sharp waste management from their healthcare provider while $20.5 \%$ had similar information from needle seller, chemist and or friend (7). According to a study done in Philippine factors that negatively affect safe disposal of used insulin injection devices include longer duration of diabetes mellitus and longer duration of insulin use (9). Similarly, a study done in Malaysia showed that duration of diabetes is one of the known influencing factors for diabetes self-care practices and there is a significant association between duration of diabetes and sharp return at healthcare facilities (10). However, there is a lack of data regarding the knowledge and self-reported practice of diabetes patients towards used insulin injection device disposal at house hold level in Addis Ababa. The purpose of the present study is therefore to assess the knowledge and self- reported practice of diabetes patients about insulin injection device disposal and associated factors in Addis Ababa, Ethiopia. 


\section{Method And Materials}

\subsection{Study design and setting}

Hospital based cross-sectional study design was used to asses the knowledge and practice of insulin injection devices disposal and associated factors among diabetes patients in Addis Ababa. The study participants were recruited from the Diabetes Clinic at Tikur Anbessa Specialized Teaching Hospital from March to May 2020. Tikur Anbessa Hospital is the single largest referral hospital in Ethiopia located in the capital city, Addis Ababa. Diabetes clinic is one of the various specialty clinics hosted by the hospital and it serves diabetes patients that come from all corners of the country through the referral system.

\subsection{Population and Sampling}

Adult patients with Type 1 and type 2 diabetes mellitus who use insulin injection and on follow up care at the diabetes clinic of Tikur Anbessa Specialized Teaching Hospital were included in the study. The researcher had chosen the 2-month follow-up period for data collection to avoid duplication of the cases as patients return to the clinic every 2 months. About 600 patients visited the clinic in the 2-month period. Every third person was selected and who meet the inclusion criteria was included. Thus, atotal of 182 participants were selected through a systematic sampling procedure.

\subsection{Data Collection Tools and Procedure}

Data was collected using an interviewer administered standardized structured questionnaire adopted from previous studies $(3,7)$. The final questionnaire consisted of 34 items and divided into five parts. These include 7 items for generating socio-demographic information, 3 items for assessing participants' awareness of safe sharp disposal, 4 items on clinical variables such as duration of diabetes and insulin use, 12 items for measuring knowledge of insulin injection device disposal, and 9 items for assessing the self-reported practice of insulin device disposal. We have computed total composite scores and median score both for the knowledge and self-reported practice of insulin injection device disposal. Score above the median was considered indicative of adequate knowledge and good selfreported practice of insulin injection device disposal among the study participants.

Data collection tool which was first prepared in English language was translated into Amharic language using a bilingual translator. Then it was back translated to English by another bilingual translator to check for accuracy of the translation and conceptual consistency. Two fourth year BSc nursing students of Addis Ababa University and two health professionals were recruited for data collection and supervision respectively. The questionnaire was pre-tested on $5 \%$ of the sample size in another to assess clarity and understandability of the tool before the actual data collection. The questionnaire was revised based on pre-test data. Then the questionnaires were distributed to the eligible participants in the service waiting area of the diabetic clinic after obtaining an informed consent. The data collectors gathered the completed questionnaire and checked for completeness. The whole process was supervised by the data collection supervisors and the principal investigator.

\subsection{Statistical Analysis}

The collected data was entered into EpiData version 4.6 and cleaned. Then it was transported to the Statistical Package for the Social Sciences (SPSS) software version 25.0 and analyzed. The descriptive statistics are summarized using frequencies and percentages. Bivariate and multiple logistic regression models were used to identify variables associated with the participants' knowledge and self-reported practice of insulin injection device disposal. Variables with p-value less than 0.25 in the bivariate logistic regression models were selected for multiple 
logistic regression analysis. Odds ratios with $95 \%$ confidence intervals and p-values $<0.05$ were used to declare the statistical significance of association between variables.

\subsection{Ethical Considerations}

\section{Ethical approval}

was obtained from the Institutional Review Board (IRB) of College of Health Sciences at Addis Ababa University. Letter of permission to conduct the study in the Diabetes Clinic was granted from the administration of Tikur Anbessa Specialized Hospital. Written informed consent was obtained from each study participant. The data obtained were identified and all the completed questionnaires had been accessed only by the research team in order to keep confidentiality of the study participants.

\section{Results}

\section{General Socio-demographic Characteristics}

One hundred eighty two adult diabetes patients participated in this study, with 93\% response rate. The mean age of the participants was $51.45 \pm 14.8$ with the age range of 18 to 82 years, $104(57.1 \%)$ were female, and the majority ( $n=$ $136,[74.7 \%]$ were married. More than a third of the participants $(n=66,[36.3 \%])$ were house wife, $30(16.5 \%$ government servant, 41 (22.5\%) were self- employed, and 18 (9.9\%) private company employee. About one-third of the participants $(n=61,[33.5 \%])$ have attended secondary education, 165 (90.7\%) were urban residents, and 86 (47.3\%) earn less than 1500 ETB monthly (Table 1).

\section{Table 1: Socio-demographic characteristics of the study participants}




\begin{tabular}{|c|c|c|}
\hline Variables & & Frequency $\mathrm{n}(\%)$ \\
\hline \multirow[t]{2}{*}{ Sex } & Male & $78(42.9)$ \\
\hline & Female & $104(57.1)$ \\
\hline \multirow[t]{4}{*}{ Age, in year } & $<25$ & $10(5.5)$ \\
\hline & $25-39$ & $26(14.3)$ \\
\hline & $40-59$ & $80(44)$ \\
\hline & $>=60$ & $66(36.3)$ \\
\hline \multirow[t]{3}{*}{ Marital status } & Single & $26(14.3)$ \\
\hline & Married & $136(74.7)$ \\
\hline & Others (widowed, divorced) & $20(11)$ \\
\hline \multirow[t]{6}{*}{ Occupation } & House wife & $66(36.3)$ \\
\hline & Government servant & $30(16.5)$ \\
\hline & Student & $6(3.3)$ \\
\hline & Self employed & $41(22.5)$ \\
\hline & Private company worker & $18(9.9)$ \\
\hline & Other & $21(11.5)$ \\
\hline \multirow[t]{4}{*}{ Educational status } & Illiterate & $27(14.8)$ \\
\hline & Primary & $44(24.2)$ \\
\hline & Secondary & $61(33.5)$ \\
\hline & College and above / & $50(27.4)$ \\
\hline \multirow[t]{2}{*}{ Residence } & Urban & $165(90.7)$ \\
\hline & Rural & $17(9.3)$ \\
\hline \multirow[t]{5}{*}{ Monthly income } & $<15000$ ETB & $86(47.3)$ \\
\hline & 1500-3000 ЕТВ & $51(28)$ \\
\hline & 3000-4500 ЕТВ & $11(6)$ \\
\hline & 4500-6000 ЕТВ & $24(13.2)$ \\
\hline & $>6000$ ETB & $10(5.5)$ \\
\hline
\end{tabular}

\subsection{Knowledge toward insulin injection devices disposal}

Twelve questions were asked to assess the participants' knowledge about insulin injection devices disposal. This 12item tool consisted of both positive questions which were represented as true or false response options. For a positive question the 'true' response option was scored as 1 and the 'false' response option was scored as 0 . For a negative question the 'false' response option was scored as 1 and the 'true' response option was scored as 0 . Then the total score was computed and ranged from 0 to12. A median score of 8 was used to classify subjects into two as having adequate knowledge (scored $\geq 8$ ) and inadequate knowledge (scored $<8$ ). More than half of participants $(54 \%)$ scored 
below the median score of 8 on the knowledge questionnaire and considered as having inadequate knowledge (Table 2). Majority of the participants $(n=168,[92.3 \%]$ ) did not know how to dispose lancets after use.

\section{Table 2: Level of knowledge of respondents toward insulin injection device disposal}

\begin{tabular}{|lll|}
\hline Level of knowledge & Frequency & Percentage \\
\hline Adequate knowledge & 84 & 46 \\
\hline Inadequate knowledge & 98 & 54 \\
\hline
\end{tabular}

\subsection{Practice towards insulin injection device disposal}

A 9-item tool was used for assessing the participants' self-reported practice of insulin injection device disposal. The 9item tool consisted of both positive and negative questions. For a positive question the 'true' response option was scored as 1 and the 'false' response option was scored as 0 . For a negative question the 'false' response option was scored as 1 and the 'true' response option was scored as 0 . Then the total score was computed and ranged from 0 to 9. A median score of 7 was used to classify subjects into two as having good practice (scored $\geq 7$ ) and poor practice (scored $<7$ ). Majority of respondents $(73.1 \%)$ had poor practice of insulin injection device disposal (Table 3$)$. About $72 \%$ of respondents place insulin injection devices in their house hold garbage bag and $69.2 \%$ did not bring used insulin injection devices back to home when they travel outside and they threw it on street, toilet and river.

Table 3: Level of the participants' practice of insulin injection device disposal

\begin{tabular}{|lll|}
\hline \multicolumn{1}{|c|}{ Level of practice } & Frequency & Percentage \\
\hline Good practice & 49 & 26.9 \\
\hline Poor practice & 133 & 73.1 \\
\hline
\end{tabular}

\subsection{Factors associated with knowledge score of study participants}

In the bivariate logistic regression analysis, age group, marital status, educational status, occupation and residence, advice from HCP, information from pharmacist/friends, duration of insulin use, and type of DM have showed statistically significant association with the participants' knowledge of insulin device disposal. However, in multiple regression model age, marital status, education, residence, type of diabetes, source of information, and duration of insulin use significantly associated with knowledge of insulin injection device disposal (Table 4). Compared to participants who were less than 25 years old those in age group between 25 to 39 years old were 8 times more likely to have adequate knowledge $(\mathrm{AOR}=8.012,95 \% \mathrm{Cl}=2.168,29.600, p$-value $=0.02)$. Participants in marriage were $62 \%$ $(A O R=0.382,95 \% \mathrm{Cl}=0.152,0.950, p$-value $=0.014)$ and those in other marital status group (divorced and widowed) were $93 \%(A O R=0.071,95 \% \mathrm{Cl}=0.016,0.320, p$-value $=0.01)$ less likely to have adequate knowledge compared to those who were single. Compared to participants who were illiterate those who had attended secondary school were 
$81 \%$ less likely to have adequate knowledge $(A O R=0.193,95 \% \mathrm{Cl}=0.056,0.660, p$-value $=0.009)$. Urban residents compared to rural residents were $80 \%$ less likely to have adequate knowledge $(A O R=0.197,95 \% \mathrm{Cl}=0.053,0.730, p$ value $=0.015)$. Participants with type 1 diabetes were 2.14 time more likely to have adequate knowledge than those with type 2 diabetes $(\mathrm{AOR}=2.14,95 \% \mathrm{Cl}=1.12,4.00, p$-value $=0.020)$. Participants who received information from pharmacist or friends were $64 \%$ less likely to have adequate knowledge compared to those who did not receive information from the said sources $(A O R=0.358,95 \% \mathrm{Cl}=0.129,0.990, p$-value $=0.036)$. Compared to participants who used insulin injection for more than 5 years those who used for 5 years and below were $67 \%$ less likely to have adequate knowledge $(\mathrm{AOR}=0.332,95 \% \mathrm{Cl}=0.154,0.710, p$-value $=0.014)$.

Table 4: Factors associated with knowledge of insulin injection device disposal

\begin{tabular}{|c|c|c|c|c|c|c|}
\hline \multirow[t]{2}{*}{ Variables } & & \multicolumn{2}{|c|}{ Knowledge } & \multirow{2}{*}{$\begin{array}{l}\text { Crude Odds Ratio } \\
\text { (COR), } 95 \% \mathrm{Cl}\end{array}$} & \multicolumn{2}{|c|}{ Adjusted Odds Ratio (AOR) } \\
\hline & & $\begin{array}{l}\text { Inadequate } \\
\text { (n) }\end{array}$ & $\begin{array}{l}\text { Adequate } \\
\text { (n) }\end{array}$ & & $\begin{array}{l}p \\
\text { value }\end{array}$ & $95 \% \mathrm{Cl}$ \\
\hline \multirow[t]{5}{*}{ Age group } & $<25$ & 4 & 6 & 1 & & 1 \\
\hline & $25-39$ & 7 & 19 & $2.308(0.593,0.9)$ & 0.02 & $8.012(2.168,29.6)$ \\
\hline & $40-59$ & 47 & 33 & $4.176(1.540,11.32)$ & 0.170 & $0.23(0.036,1.44)$ \\
\hline & $>60$ & 40 & 26 & $1.08(0.556,2.10)$ & 0.108 & 0.213(0.033, \\
\hline & & & & & & 1.373) \\
\hline \multirow[t]{3}{*}{ Marital status } & Single & 8 & 18 & 1 & & 1 \\
\hline & Married & 73 & 63 & $0.384(0.156 .0 .94)$ & 0.014 & $0.382(.152,0.95)$ \\
\hline & others & 17 & 3 & $\begin{array}{l}0.078(.0018,0 . \\
346)\end{array}$ & 0.01 & $0.071(.016 .0 .32)$ \\
\hline \multirow{4}{*}{ Education } & Illiterate & 18 & 9 & 1 & & 1 \\
\hline & Primary & 33 & 11 & $0.235(0.87,0.637)$ & 0.045 & $0.261(.067,1.026)$ \\
\hline & Secondary & 31 & 30 & $0.157(0.63,0.88)$ & 0.009 & $0.193(.056,0.66)$ \\
\hline & $\begin{array}{l}\text { College } \\
\text { \&above }\end{array}$ & 16 & 34 & $.455(0.209,0.991)$ & 0.0174 & $5.00(0.184,1.3)$ \\
\hline \multirow[t]{2}{*}{ Residence } & Urban & 84 & 8 & $0.22(0.62,0.802)$ & 0.015 & $0.197(0.053,0.73)$ \\
\hline & Rural & 14 & 3 & 1 & & 1 \\
\hline \multirow[t]{2}{*}{ Type of DM } & Type 1 & 24 & 36 & $2.31(1,2,4.3)$ & 0.020 & $2.14(1.12,4.0)$ \\
\hline & Type 2 & 74 & 48 & 1 & & 1 \\
\hline \multirow{2}{*}{$\begin{array}{l}\text { Information from } \\
\text { pharmacist/friend }\end{array}$} & Yes & 18 & 32 & $.366(.186, .718)$ & 0.036 & $0.358(0.129,0.99)$ \\
\hline & No & 80 & 52 & 1 & & 1 \\
\hline \multirow[t]{2}{*}{$\begin{array}{l}\text { Duration of } \\
\text { insulin use }\end{array}$} & $\begin{array}{l}1 \mathrm{mon}- \\
5 y e a s\end{array}$ & 32 & 11 & $0.331(.145, .66$ & 0.014 & $0.332(0.154,0.71)$ \\
\hline & $>$ yyears & 66 & 73 & 1 & & 1 \\
\hline
\end{tabular}




\section{Factors associated with practice of insulin injection device disposal}

In bivariate logistic regression analysis, age group, marital status, occupation, educational level, duration of insulin use, advice from health care provider (HCP), type of DM, and knowledge of insulin injection device disposal were significantly associated with self-reported insulin injection device disposal practice. In multiple logistic regression models, age, marital status, educational level, advice from HCP, duration of insulin use, type of DM, and knowledge of insulin device disposal have shown statistically significant association with self-reported insulin device disposal practice (Table 5). Compared to participants aged less than 25 years old those in age group between 25 and 39 years were $90 \%$ less likely to have good self-reported insulin injection disposal practice $(\mathrm{AOR}=0.101,95 \% \mathrm{Cl}=0.019,0.535$, $p$-value $=0.007)$. Participants in marriage were $86 \%$ less likely to have good self-reported practice than those who were single $(\mathrm{AOR}=0.141,95 \% \mathrm{Cl}=0.049,0.406, p$-value $<0.001)$. Compared to illiterate participants those who attended primary education were $84 \%$ less likely to have good self-reported practice $(A O R=0.158,95 \% \mathrm{Cl}=0.028$, $0.903, p$-value $=0.038)$. Participants who received information from pharmacist or friends were $59 \%$ less likely to good self-reported practice compared to those who did not receive information from the said sources $(A O R=0.407$, $95 \% \mathrm{Cl}=0.169,0.980, \mathrm{p}$-value $=0.046)$. Participants who used insulin for more than 5 years were $77 \%$ less likely to have good self-reported practice than those who used insulin for 5 years or below $(A O R=0.230,95 \% \mathrm{Cl}=$

$0.077,0.690, p$-value $=0.009)$. Participants with type 1 diabetes were 2.1 times more likely to have good self-reported practice than those with type 2 diabetes $(A O R=2.1,95 \% \mathrm{Cl}=1.054,4.200, p$-value $=0.035)$. Furthermore, participants who had adequate knowledge of insulin injection device disposal were 2.5 time more likely to have adequate selfreported practice compared to those who had inadequate knowledge $(\mathrm{AOR}=2.5,95 \% \mathrm{Cl}=1.025,6.300, p$-value $=$ 0.044).

Table 5: Factors associated with self-reported practice of insulin injection device disposal 


\begin{tabular}{|c|c|c|c|c|c|c|}
\hline \multirow[t]{2}{*}{ Variables } & & \multicolumn{2}{|c|}{$\begin{array}{l}\text { Self-reported } \\
\text { practice }\end{array}$} & \multirow[t]{2}{*}{$\begin{array}{l}\text { Crude Odds Ratio (COR), } \\
95 \% \mathrm{Cl}\end{array}$} & \multicolumn{2}{|c|}{ Adjusted Odds Ratio (AOR) } \\
\hline & & Poor & Good & & $\begin{array}{l}\mathrm{P} \text { - } \\
\text { value }\end{array}$ & $95 \% \mathrm{Cl}$ \\
\hline \multirow[t]{4}{*}{ Age group } & $<25$ & 3 & 7 & 1 & & 1 \\
\hline & $25-39$ & 16 & 10 & $7.933(1.824,34.5)$ & 0.007 & $\begin{array}{l}0.101(0.019 \\
0.535)\end{array}$ \\
\hline & $40-59$ & 63 & 17 & $2.125(.799,5.6)$ & .389 & $0.093(.017,0.52)$ \\
\hline & $\geq 60$ & 51 & 15 & $.917(.418,2.014)$ & .306 & $0.131(.024,0.71)$ \\
\hline \multirow[t]{3}{*}{ Marital status } & Single & 9 & 17 & 1 & & 1 \\
\hline & Married & 107 & 29 & $10.704(2.462,46.52)$ & 0.000 & $0.141(.049,0.406)$ \\
\hline & Other & 17 & 3 & $1.536(.421,5.603)$ & .563 & $0.624(0.127,3.07)$ \\
\hline \multirow[t]{4}{*}{ Education } & Illiterate & 24 & 3 & 1 & & 1 \\
\hline & Primary & 35 & 9 & $2.057(.504,8.393)$ & 0.038 & $0.158(0.028,0.903)$ \\
\hline & Secondary & 45 & 16 & $2.844(.753,10.743)$ & 0.341 & $0.551(0.161,1.88)$ \\
\hline & $\begin{array}{l}\text { College } \\
\text { \&above }\end{array}$ & 29 & 21 & $5.793(1.540,21.79)$ & 0.001 & $0.429(0.153,1.20)$ \\
\hline \multirow{2}{*}{$\begin{array}{l}\text { Advice from } \\
\text { HCP }\end{array}$} & Yes & 67 & 34 & $.448(.223,0.898)$ & .046 & $0.407(0.169,0.98)$ \\
\hline & No & 66 & 15 & 1 & & 1 \\
\hline \multirow{2}{*}{$\begin{array}{l}\text { Duration of } \\
\text { insulin use }\end{array}$} & $1 \mathrm{mon}-5 \mathrm{yr}$ & 39 & 4 & 1 & & 1 \\
\hline & $>5$ years & 94 & 45 & $.214(.072, .636)$ & 0.009 & $\begin{array}{l}0.230(0.077 \\
0.690)\end{array}$ \\
\hline \multirow{3}{*}{ Type of DM } & Type1 & 37 & 23 & $2.3(1.16,4.51)$ & 0.035 & $2.1(1.054,4.2)$ \\
\hline & Type 2 & 96 & 26 & 1 & & 1 \\
\hline & Inadequate & 83 & 15 & 1 & & 1 \\
\hline Knowledge & Adequate & 50 & 34 & $3.76(1.87,7.6)$ & 0.044 & $2.5(1.026,6.3)$ \\
\hline
\end{tabular}

\section{Discussion}

This study assessed the knowledge and self-reported practice of diabetes patients toward insulin injection device disposal and associated factors in Addis Ababa, Ethiopia. The issue of insulin injection device disposal has not been widely before. Syringe disposal without effective waste disposal system opens a new portal of transmission of blood borne pathogen from patients to general community (3). Disposal of used injection equipment at open place could increase the risk of transmission to children, who play with syringes and get pricked, and results in transmission of blood-borne infection like HIV, HBV, and HCV in the community (8).

Majority of the participants in this study had inadequate knowledge of insulin injection device disposal. But, this finding shows that the participants in our study had better knowledge of insulin injection device disposal than the 
studies reported from India and Gondar town in Ethiopia $(3,7)$. This might be due to difference in the way diabetes self-management education program is being run in these setting and increasing awareness of the patient population about the issue with change in time period. Regardless of lack of national guidelines for diabetes patients about insulin injection device disposal at home in Ethiopia, patients from Addis Ababa may have more access to information to learn about waste management through mass media as well as social media compared to those in Gondar town.

The current study revealed that majority of respondents had poor practice of insulin injection device disposal. However, this finding shows that our study participants had better practice when compare to the findings of a study from Indian (7).This might be related to differences in health education modalities and access to sharp disposal facilities at home and during travel.

Education level is associated with knowledge level as respondents who attended college less likely have adequate knowledge of insulin injection device disposal. This finding was in disagreement with the findings of the study reported from Gonder town (3). However, a study from South Africa reported that there were no significant associations between education level and correct disposal of insulin injection devices (11). This implies that education level may not be the determining factor that influences the patients' knowledge of insulin injection device disposal.

This study showed patients from urban areas had low knowledge of insulin injection disposal than patients from rural areas. This finding is in agreement with the findings of studies from Pakistan and Gonder town $(3,8)$. This indicate that unlike the expectation of many patients from urban centers who are considered as having more access to information than rural residents are not well off when it comes to the knowledge regarding insulin injection device disposal. Therefore, further research is warranted to investigate to identify why urban patients who deemed as having more access to information are not better off in terms of knowledge of insulin injection device disposal.

This study revealed that participants who received information from pharmacists or friends were not well off than those who didn't receive from the said parties in terms of both knowledge and practice of insulin injection device disposal. This is contrary to the findings of the studies from Gonder town (3) and India and USA (7) which showed that information from health care professionals played an important role in disposal of insulin injection device.

Our study showed that diabetes patients who have used insulin injection for more than 5 years have better knowledge of insulin injection device disposal but have less practice of it compared to those who were on insulin injection for 5 years or below. This findings corroborate with that of studies done in Philippine and Gonder town $(3,9)$. However, a study from Malaysia reported that patients who had used insulin for less than five years had almost three times higher knowledge and good practice compared to those who used insulin for greater than five years(10). Contrarily, our study revealed the nonalignment of knowledge and practice of insulin injection device disposal among the study participants in terms of the duration of insulin injection use. This implies the need for future study to investigate other contextual factors potential for creating this nonalignment between knowledge and practice on the backdrop of the duration of insulin use.

This study revealed that patients with type1 diabetes were better off with regard to both knowledge and practice of insulin injection device compared to those with type 2 diabetes. This may be related to the longer time of exposure of type 1 diabetes to information and experience on injection device disposal since most of them start insulin injection at earlier age than type 2 diabetes. Besides, this finding imply the need to give emphasis to address knowledge and practice gap that insulin injecting type 2 diabetes have regarding safe disposal of insulin injection devices at home. 
Furthermore, our study showed positive association between having adequate knowledge of insulin injection device disposal and its practice. This indicates that increasing diabetes knowledge of insulin injection device disposal is paramount for improving their practice. Therefore, future interventions need to focus on increasing diabetes patients' knowledge of insulin injection device disposal.

\section{Conclusion}

Our study showed that the knowledge and practice of safe insulin injection device disposal were lowere among the study participants. Sociodemographic and clinical variables such as age, marital status, residence, education level, and information, type of diabetes, and duration of insulin use emerged as significant predictors of knowledge and practice of insulin injection device disposal. Further research is also warranted to identify why urban patients who deemed as having more access to information are not better off in terms of knowledge of insulin injection device disposal and the contextual factors potential for creating nonalignment between knowledge and practice of insulin injection device disposal on the backdrop of the duration of insulin use.

\section{Abbreviations}

AOR

Adjusted Odds Ratio

COR

Crude Odds Ratio

$\mathrm{Cl}$

Confidence interval

DM

Diabetes mellitus

ETB

Ethiopian Birr/currency

SPSS

Statistical Package for Social Sciences

\section{Declarations}

\section{Acknowledgements}

We would like to thank the patients who volunteered to provide data for this study.

\section{Author's contribution}

A.L. and F.A. and A.F. worked in the conception and design of the study. A.L. collected, analyzed interpreted the data, and drafted the manuscript. F.A. and A.F. monitored and evaluated the data. F.A. and A.F. critically revised and edited the manuscript. All authors read and approved the manuscript.

\section{Funding}

The study was funded by Addis Ababa University. 


\section{Availability of data and materials}

The dataset used for the study is not publicly available in order to maintain data security but is available from corresponding author on reasonable request.

\section{Ethical Approval}

Ethical approval for this study was obtained from the Institutional Review Board (IRB) of Addis Ababa University, College of Health Sciences. Permission to conduct the research was obtained from the authorities in the study settings and informed consents were secured from each participant. Confidentiality of the participant was maintained by not including names or any personal identifier during data collection, analysis, and reporting. Participants' right to refuse participation, not to answer any question they don't want to, or withdraw participation after enrolling was fully respected.

\section{Consent for publication}

Not required.

Competing interests the authors declare that they have no competing interests.

\section{References}

1. Cunha GHd, Barbosa RVA, Fontenele MSM, Lima MAC, Franco KB, Fechine FV. Insulin therapy waste produced in the households of people with diabetes monitored in Primary Care. Revista brasileira de enfermagem. 2017;70(3):618-25.

2. Saeedi P, Petersohn I, Salpea P, Malanda B, Karuranga S, Unwin N, et al. Global and regional diabetes prevalence estimates for 2019 and projections for 2030 and 2045: Results from the International Diabetes Federation Diabetes Atlas. Diabetes Research and Clinical Practice. 2019;157:107843.

3. Basazn Mekuria A, Melaku Gebresillassie B, Asfaw Erku D, Taye Haile K, Melese Birru E. Knowledge and selfreported practice of insulin injection device disposal among diabetes patients in Gondar town, Ethiopia: A crosssectional study. Journal of Diabetes Research. 2016;2016.

4. Majumdar A, Sahoo J, Roy G, Kamalanathan S. Improper sharp disposal practices among diabetes patients in home care settings: need for concern? Indian Journal of Endocrinology and Metabolism. 2015;19(3):420.

5. Biçer EK. An Important Environmental Risk from Patients with Diabetes using Insulin: Disposal of Medical Waste. Journal of Diabetes Research.5(2):182-8.

6. Sharif S, Al Sha'rawy M, Mhithawi H, Alketbi A, Sharif R, Rashrash M. Assessment of Awareness of Diabetic Patients Regarding Safe Disposable of their Insulin Syringes and Sharps in the UAE. Austin J Public Health Epidemiol. 2018;5(2):1072.

7. Singh AP, Chapman RS. Knowledge, attitude and practices (KAP) on disposal of sharp waste, used for home management of type-2 diabetes mellitus, in New Delhi, India. Journal of Health Research. 2011;25(3):135-40.

8. Ishtiaq O, Qadri AM, Mehar S, Gondal GM, Iqbal T, Ali S, et al. Disposal of syringes, needles, and lancets used by diabetic patients in Pakistan. Journal of infection and public health. 2012;5(2):182-8.

9. Quiwa L, Jimeno C. Knowledge, attitudes and practices on the disposal of sharps in patients of the UP-Philippine General Hospital Diabetes Clinic. Journal of the ASEAN Federation of Endocrine Societies. 2014;29(2):141. 
10. Hasan UA, Mohd Hairon S, Yaacob NM, Daud A, Abdul Hamid A, Hassan N, et al. Factors Contributing to Sharp Waste Disposal at Health Care Facility Among Diabetic Patients in North-East Peninsular Malaysia. International Journal of Environmental Research and Public Health. 2019;16(13):2251.

11. Govender D, Ross A. Sharps disposal practices among diabetic patients using insulin. SAMJ: South African Medical Journal. 2012;102(3):163-4. 